\title{
SADISMO, MASOQUISMO E RELAÇÕES DE PODER NO CONTO “O CORPO”, DE CLARICE LISPECTOR
}

\section{SADISM, MASOCHISM AND POWER RELATIONS IN THE SHORT STORY "O CORPO", BY CLARICE LISPECTOR}

Jhonatan Leal da Costai

RESUMO: O conto "O corpo", publicado por Clarice Lispector no livro A via crucis do corpo, em 1974, narra a história de um homem bígamo que se vê em conflito com as suas duas esposas. Casados sob o mesmo teto, Xavier, Carmem e Beatriz sofrem com as consequências provenientes da realização de seus desejos: Ele, o de satisfazer suas vontades em detrimento de suas esposas, elas, o de não permitir mais nenhum tipo de humilhação por parte do marido. Armado esse impasse, o trio assume posturas e toma decisões que vem a desembocar em dores físicas e/ou psíquicas, culminando em um desenlace trágico e sanguinolento da união conjugal. Nesse sentido, objetivamos, neste trabalho, investigar uma possível aplicação, nesses seres ficcionais, da teoria psicanalítica a respeito do sadismo, do masoquismo e, consequentemente, do sadomasoquismo. Para tanto, faremos uso dos estudos desenvolvidos por Freud (2016), Laplanche e Pontalis (2016), McWilliams (2014), dentre outros. Nas considerações deste trabalho, apresentaremos achados a respeito da subversão feminina e das relações de poder entre homens e mulheres sob a ótica de uma escritora que não economizou em plasmar sua própria subjetividade na produção artística de sua obra.

PALAVRAS-CHAVE: Sadismo. Masoquismo. Sadomasoquismo. Clarice Lispector.

ABSTRACT: The short story "O corpo" ("The body"), published by Clarice Lispector in the book $A$ via crucis do corpo (The via crucis of the body), in 1974, tells the story of a bigamy man who finds himself in conflict with his two wives. Married under the same roof, Xavier, Carmem and Beatriz suffer the consequences from fulfilling their desires: He, from satisfying his desires over his wives', they, from taking no further of their husband's humiliation. Problem built, the trio takes positions and make decisions that come to end in physical and / or psychic pain, culminating in a tragic and bloody outcome of the marital union. In this sense, we aim, in this text, to investigate a possible application, in these fictional characters, of psychoanalytic theory regarding sadism, masochism and, consequently, sadomasochism. To do so, we will use the studies developed by Freud (2016), Laplanche and Pontalis (2016), McWilliams (2014), among others. In the considerations, we will present findings about female subversion and power relations between men and women from the point of view of a writer who did not spare to translate her own subjectivity into the artistic production of her work.

KEYWORDS: Sadism. Masochism. Sadomasochism. Clarice Lispector.

Submetido em: 29 nov. 2018. Aprovado em: 16 out. 2018.

i Universidade Federal da Paraíba. E-mail: jhonatan_leal@hotmail.com. 


\section{Introdução}

A abertura do livro de contos $A$ via crucis do corpo, de autoria de Clarice Lispector, publicado em 1974, traz um prefácio, intitulado "Explicação", no qual a escritora prepara os seus leitores para o que chamou de "livro de encomenda". Segundo ela, o poeta Álvaro Pacheco, seu editor na Artenova, Ihe pediu que escrevesse três histórias que, de fato, tinham acontecido. "A conversa telefônica foi na sexta-feira. Comecei no sábado. No domingo de manhã as três histórias estavam prontas: 'Miss Algrave', 'O Corpo' e 'Via Crucis'”. (LISPECTOR, 1998, p. 11).

O que vemos, pois, nos 14 textos ficcionais deste tomo - 13 contos mais o prefácio "Explicação" - como também assegura Ana Cristina Chiara (1998), é a faceta de uma Clarice Lispector que ainda não havia sido explorada, até então, em sua escritura ficcional. O espanto da autora de Perto do coração selvagem (1944), aqui, na Via crucis do corpo, se transforma em escândalo. Do mesmo modo, na mesma intensidade, o sobressalto passa a ser convertido em ferocidade. Atando as pontas de todas as narrativas, de maneira central, o corpo: o verdadeiro protagonista de todas essas tramas.

Como o corpo de Xavier, que vai parar sob sete palmos do jardim de sua própria casa para servir de adubo a um roseiral. Personagem do conto "O corpo", objeto de nosso estudo, Xavier é um empresário bem-sucedido de 47 anos, "truculento e sanguíneo. Muito forte esse homem". Representação estereotipada da virilidade masculina, tal personagem é esculpida pelo narrador com tintas fortes a respeito de sua brutalidade, fome, impaciência e sede por trabalho, mulheres e dinheiro. "Todo mundo sabia que Xavier era bígamo: vivia com duas mulheres". (LISPECTOR, 1998, p. 21).

Carmem e Beatriz eram as suas respectivas esposas. A primeira, com 39 anos, e a segunda, com 50. E, diferente do que ocorre com Xavier, as personagens mulheres desta narrativa tendem a ser erguidas, física e psicologicamente, com um maior grau de subjetividade, mais distantes dos papéis socialmente atribuídos aos gêneros. "Beatriz comia que não era vida: era gorda e enxundiosa. Já Carmem era alta e magra”. (LISPECTOR, 1998, p. 21). 
O conflito nesta narrativa é endossado quando Xavier, não satisfeito com as duas mulheres que dispõe em casa, começa a ir em busca de novas aventuras afetivo-sexuais fora do matrimônio. Autoritário, despreocupado com a implicação de suas ações no modo como as suas esposas se compreendem, e transformando-as em meros objetos a serviço de seu bel prazer, Xavier aprende a usar da humilhação e da indiferença como instrumentos de exercício do poder. Ele só não esperava que Carmem e Beatriz, subjugadas e rebaixadas, viessem a se rebelar de maneira brutal e violenta.

Nesse sentido, partiremos da hipótese, neste artigo, de que essa tríade de seres ficcionais arquitetados por Clarice Lispector é movida, no interior da diegese, por estruturas psíquicas permeadas por sadismo, masoquismo e/ou sadomasoquismo. Para tanto, em um primeiro momento, fundamentaremos tais terminologias segundo a teoria psicanalítica, aqui defendida, principalmente, por Sigmund Freud (2016), e apoiada por Jean Laplanche e Pontalis (2016), McWilliams (2014), Jean-Michel Quinodoz (2007), dentre outros.

$\mathrm{Na}$ sequência, aplicaremos, nas personagens do conto "O corpo", as teorias psicanalíticas apresentadas na fundamentação teórica, com a finalidade de descobrirmos se existe a possibilidade de enxergarmos configurações de sadismo, masoquismo e/ou sadomasoquismo na maneira como Xavier, Carmem e Beatriz foram representadas.

Por fim, exporemos nossas considerações, apresentando dados que comprovam ou refutam nossas hipóteses a respeito da estrutura psíquica elaborada ficcionalmente por Clarice Lispector para as personagens em questão. Acreditamos na importância e difusão da relação dos estudos literários com os saberes psicanalíticos, pois, conforme defende Élisabeth Ravoux Rallo (2005, p. 219), "a psicanálise e a crítica literária fazem a mesma coisa: interpretam. E o fenômeno da interpretação é o pressuposto básico: interpretar é procurar sentido ou, decerto com mais exatidão, dar sentido".

\section{O corpo que sofre, o corpo que faz sofrer}

A obra Três ensaios sobre a teoria da sexualidade, publicada em 1905, tem sido considerada por muitos como a mais importante de Freud depois de $A$ 
interpretação dos sonhos (1900), conforme assegura Jean-Michel Quinodoz (2007, p. 71): "Nela Freud desafia abertamente a opinião popular e os preconceitos vigentes sobre a sexualidade". Neste livro, o pai da psicanálise alargou a compreensão da sexualidade para além da noção em que era conservada por suas antigas definições, além de pôr em evidência que a sexualidade humana já se perfaz na primeira infância, período muito mais precoce do que era defendido até então. É neste volume, também, que Freud vem tratar das "fixações de metas sexuais provisórias", dentre elas, o sadismo e o masoquismo.

Criados pelo psiquiatra alemão Krafft-Ebing em 1900, esses dois termos foram explanados na obra Psychopathia sexualis e se originaram a partir da observação do trabalho de dois escritores: Marquês de Sade e Leopold von Sacher-Masoch. Se nas obras de Sade as personagens costumavam procurar 0 orgasmo via agressão, violência e subjugação do outro, nas de Sacher-Masoch elas o buscavam, inconscientemente, por meio do tormento e da humilhação de si mesmas. Sendo assim, Krafft-Ebing cunhou as categorias sexuais de sadismo em homenagem ao Marquês de Sade, e de masoquismo em referência a SacherMasoch.

Freud (2016, p. 51), que dava ênfase às origens sexuais para a maioria dos comportamentos humanos, considerou natural aplicar esses termos para padrões aparentemente não sexuais de dores (auto)infligidas: "A mais frequente e mais significativa de todas as perversões, a inclinação a infligir dor ao objeto sexual e sua contrapartida, recebeu de Krafft-Ebing os nomes de sadismo e masoquismo, para suas formas ativa e passiva".

Nos referidos ensaios, o médico austríaco argumenta que a sexualidade da maioria dos homens tende a expor um elemento de agressividade, de tendência a dominar, explicada biologicamente pela necessidade de romper a resistência do objeto sexual sem a precisão de cortejá-lo. "O sadismo corresponderia, então, a um componente agressivo do instinto sexual que se tornou independente, exacerbado, e foi colocado na posição principal mediante deslocamento". (FREUD, 2016, p. 52). Nessa perspectiva, o conceito de sadismo, em sua configuração mais extrema, perpassaria pelos seguintes estágios: o de uma atitude incialmente ativa, seguida por uma posição violenta 
ante o objeto sexual, que culmina no vínculo da satisfação com a humilhação e o mau trato deferido contra o objeto de desejo.

No mesmo viés, o sentido de masoquismo, para Freud (2016), considera todos os comportamentos passivos ante o sexo e o objeto sexual, de modo que a sua forma mais acentuada consiste em vincular satisfação com o sofrimento físico ou psíquico suportados pelo próprio sujeito. Ele também acrescenta que o prazer inconsciente com toda espécie de humilhação e submissão, ou seja, o masoquismo, não é senão uma continuação do sadismo, só que desta vez, voltado contra o próprio indivíduo, que passa a se colocar no lugar de objeto sexual: "Um sádico sempre é, simultaneamente, um masoquista, embora o lado ativo ou o lado passivo da perversão esteja mais desenvolvido nele e constitua sua atividade sexual predominante". (FREUD, 2016, p. 54).

Para além de Freud, mas ancorado nele, os estudos psicanalíticos da contemporaneidade, como os desenvolvidos por Joel Birman (2009, p. 135), consideram que o desejo original do sadismo não se constitui meramente na pretensão de humilhar, controlar e infligir dor ao outro, mas, antes, de asseverar o poder e possibilidades que detém o próprio sujeito: "Com efeito, o que se pretende originariamente é afirmar a potência do ser".

Por outro lado, se deixando persuadir por discursos politicamente corretos, Nancy McWilliams (2014, p. 294) combate as leituras que associam masoquismo a prazer pela crueldade, humilhação e sofrimento:

\footnotetext{
Gostaria de ressaltar que o termo 'masoquismo', do modo como é usado pelos psicanalistas, não tem a conotação de um amor pela dor e pelo sofrimento. A pessoa que se comporta de forma masoquista enfrenta a dor e o sofrimento na esperança, consciente ou inconsciente, de alcançar algum bem maior.
}

Desse modo, para McWilliams (2014), fatores como medo de ser abandonado, temor da solidão e receio de ter um ideal de felicidade destruído é o que levaria um sujeito masoquista a desenvolver uma alta tolerância às dores físicas e emocionais. A pesquisadora ainda ressalta que, nas discussões a respeito da entrada da personalidade autodestrutiva no Manual Diagnóstico e Estatístico de Transtornos Mentais (DSM), muitos estudiosos "consideravam a atribuição do masoquismo ou da autodestrutividade o mesmo que acusar uma 
pessoa de ter prazer na dor - de 'culpar a vítima'-, como se essa pessoa conscientemente abusasse de si mesma como uma forma perversa de prazer".

Como percebemos, a influência dos estudos feministas e do desconstrutivismo derridiano começam a reposicionar o modo como alguns psicanalistas reverberam os conflitos da psique. Se existem os que, de fato, sentem prazer pela dor e pelo sofrimento, estes, hoje, tendem a ter a leitura de seus desejos adaptada de acordo com a moral vigente. Resta saber, no tópico seguinte, como se portarão os homens e mulheres representados por Clarice Lispector, no conto "O corpo", ao se depararem com a dor que sofrem ou que a fazem vir a existir nos outros.

\section{"O corpo" e suas fraturas}

A tríade relacional entre Xavier, Carmem e Beatriz no conto "O corpo" se configura, inicialmente, por meio de um modelo patriarcal e, portanto, heterossexual. Ainda que os três vivessem sob o mesmo teto, as duas mulheres mantinham uma relação restrita a amizade, de modo que, na conjuntura daquele casamento, apenas o homem era favorecido pelo tripé matrimonial: "Cada noite era uma. Às vezes duas vezes por noite. A que sobrava ficava assistindo". (LISPECTOR, 1998, p. 21).

Sendo assim, por mais que a representação inicial deste relacionamento a três transpareça uma certa aura de cordialidade, é possível percebermos, através da lexicologia escolhida pelo narrador, que algo já não estava dentro da conformidade aparentada.

Se a "cada noite era uma" das esposas que era eleita para a cópula sexual com Xavier, a outra, inevitavelmente, acabava por ser preterida, "sobrava ficar assistindo". E, ainda que saibamos, em confluência a Freud (2016), que a prática do ver e do observar, denominada voyeurismo, possa ser causadora de prazer, a expressão "sobrava", utilizada pelo narrador nesse contexto, atribui um tom negativo e de pouca satisfação para a atividade vivenciada.

Desde o início desta narrativa fica expresso, portanto, a soberania do prazer masculino em oposição à insatisfação e subjugação das mulheres. Tal retrato, de perfil estritamente patriarcal, ultrapassa as práticas sexuais e se 
apresenta, também, nas atribuições destinadas para os diferentes gêneros: "Xavier trabalhava muito para sustentar as duas e a si mesmo, as grandes comidas". (LISPECTOR, 1998, p. 22).

Assim como o espaço público está para Xavier, um homem, o espaço privado se coloca para Carmem e Beatriz, as mulheres. Elas não trabalham. Ele sim. Elas se colocam como dependentes financeira, física e emocionais dele. Ele não.

Peguemos a ilustração do alimento, sempre enfatizado pelo narrador deste conto: "Beatriz comia que não era vida: era gorda e enxundiosa", "almoçaram às três horas da tarde", "Xavier bebeu vinho francês. E comeu sozinho um frango inteiro. As duas comeram o outro frango." (LISPECTOR, 1998, p. 22).

Com base nos fragmentos expostos, é possível constatar que, assim como Xavier exerce controle sobre a satisfação sexual de suas mulheres, regulando qual das duas irá para a cama com ele, também domina a satisfação delas na esfera alimentícia, visto ser ele o responsável pelas compras dos mantimentos da casa. Nesse contexto, a dominação de Xavier em relação à suas esposas ocorre, também, em padrões quantitativos. Seja na consumação sexual exercida por ele diariamente, ao passo que uma de suas mulheres geralmente fica condenada ao estado contemplativo do ato; seja no frango que ele come inteiro enquanto as duas dividem um. Em se tratando dos meios de sentir prazer, Xavier sempre busca formas de se sobrepor às suas companheiras.

Nesse ponto, cabe aplicarmos no material até então exposto as reflexões de Freud a respeito de sadismo e masoquismo.

A postura sádica, da agressividade comumente atribuída aos homens, é notadamente percebida nas ações de Xavier e em seu desejo, de ordem consciente ou inconsciente, de exercer domínio sobre as suas duas esposas. É ele quem controla as doses de prazer que elas recebem ao longo do dia, em uma atitude que pouco expressa comiseração ou empatia pelo objeto de desejo: "a que sobrava ficava assistindo". No mesmo sentido, Carmen e Beatriz, quer estejam movidas por comodidade, falta de perspectiva futura, medo de ficarem sozinhas, baixa autoestima ou fé de que as coisas melhorarão, contentam-se com o pouco que lhes é ofertado pelo homem que escolheram como amante. 
Essa posição passiva e permissiva de subjugação, diante do sexo e da vida, expõe, como apresentara Freud (2016), a arquitetura psíquica do masoquista.

O conto aprofunda psicologicamente suas personagens quando Xavier decide que, ao invés de dar prioridade a satisfação afetivo-sexual de suas duas esposas, irá em busca de novas aventuras: "E às vezes enganava a ambas com uma prostituta ótima. Mas nada contava em casa pois não era doido." (LISPECTOR, 1998, p. 22).

Nesse cenário de amor racionado, medido, sadicamente, pelo homem da casa, receber prazer do próprio marido acaba por se tornar um capital digno de ostentação: Carmem mantinha "um diário: anotava nas páginas do grosso caderno encadernado de vermelho as datas em que Xavier a procurava. Dava o diário a Beatriz para ler". (LISPECTOR, 1998, p. 23).

Se considerarmos os dizeres de Freud (2016, p. 54) de que um "sádico sempre é, simultaneamente, um masoquista", atentaremos para o fato de que, ainda que Carmen, neste ponto da narrativa, tenha o masoquismo de modo mais predominante em seu comportamento, o fato dela dar o seu diário (com os registros dos dias em que Xavier a procurara) para Beatriz ler, revela um nítido desejo de magoar e ferir a parceira. Expõe uma atitude sádica por parte da personagem até então articulada apenas pelas cores do masoquismo.

No âmbito da ação narrativa, o distanciamento de Xavier, cada vez mais acentuado pelos encontros que ele mantém com a prostituta, conduz Beatriz e Carmem a tentarem encontrar satisfação entre as duas: "E, apesar de não serem homossexuais, se excitavam uma à outra e faziam amor. Amor triste." (LISPECTOR, 1998, p. 23).

Com a ausência sexual do marido, resta às duas mulheres buscarem formas outras de alcançarem o prazer, ainda que este, por não ser estabelecido, de maneira direta, com o objeto sexual de suas escolhas, não venha a ser de todo satisfatório. Seja um "amor triste", como o é o amor de vivenciado por um masoquista.

Excitadas com a experiência homossexual, Carmem e Beatriz contam para Xavier o que haviam feito. E, outra vez, a posição tomada por ele não só as pega de surpresa como as objetifica ainda mais: "Xavier vibrou. E quis que nessa noite as duas se amassem na frente dele. Mas, assim encomendado, terminou 
tudo em nada. As duas choraram e Xavier encolerizou-se danadamente." (LISPECTOR, 1998, p. 23).

Se o perfil masoquista das personagens femininas é, nessa passagem, enfatizado pela humilhação de terem de transar juntas - mesmo sem serem homossexuais - para o marido assistir, seguido da passividade em não conseguirem cumprir o ato sexual e do choro proveniente da ineficiência do intento, o perfil sádico de Xavier se acentua com a ordenação de que as esposas transassem no exato momento em que ele exigia, bem como da raiva colérica manifestada por ele ao não ter o seu desejo atendido.

$E$, como castigo por não o satisfazerem na hora e no modo em que ele exigira, bem como por punição por terem vivenciado momentos de prazer sem a sua presença e/ou "autorização", Xavier fere Carmem e Beatriz com mais ausência de afeto: "Durante três dias ele não disse nenhuma palavra às duas." (LISPECTOR, 1998, p. 23). Mas as duas, porém, cada vez mais ancoradas uma na outra, correspondem-no com indiferença. E vão além: voltam a se amar na ausência do marido.

Xavier, então, decide aumentar a dose de violência psicológica contra as suas esposas: "Um dia Xavier veio do trabalho com marcas de batom na camisa. Não pôde negar que estivera com a sua prostituta preferida." E, dessa vez, pelo primeiro momento na narrativa, Carmem e Beatriz assumem uma posição de agressividade contra o marido: "Carmem e Beatriz pegaram cada uma um pedaço de pau e correram pela casa toda atrás de Xavier. Este corria feito um desesperado, gritando: perdão! perdão! perdão!" (LISPECTOR, 1998, p. 24).

A passagem exposta através do fragmento anterior é emblemática por três razões. Primeiro, por percebermos que quando as mulheres passam a encontrar prazer para além do provedor anteriormente elegido por elas, elas conseguem se colocar de maneira ativa diante dele, sem permitir mais desrespeito ou subjugação; segundo, pela apropriação da agressividade culturalmente destinada aos homens, em conforme ao que defendera Freud (2016), através da imagem fálica dos paus que elas empunham ao correrem atrás do marido; e, terceiro, pela mudança na postura de Xavier que, de ativo, colérico e cruel, permuta para resignado, temeroso e desesperado. 
Após este evento, Carmem e Beatriz proclamaram uma decisão: não cozinhariam mais para o marido. E, como se não bastasse, na noite deste mesmo dia, "fizeram amor na sua frente e ele roeu-se de inveja. Como é que começou o desejo de vingança? As duas cada vez mais amigas e desprezandoo”. (LISPECTOR, 1998, p. 24).

A inversão de sadismo e masoquismo entre as personagens, nesta altura do conto, torna-se mais clara. Ao saírem de uma condição passiva para uma ativa, Carmem e Beatriz substituem dor e sofrimento por raiva e agressividade. Saem de uma condição masoquista e assumem uma postura sádica. Devolvem, para Xavier, toda a carga de humilhação que dele receberam, em iguais proporções. Se recusam a cozinhar para o marido, exercendo controle sobre o alimento, controle este que estava, anteriormente, em posse de Xavier. Transam entre si e o traem sexualmente em sua ausência, assim como ele fizera com a prostituta. E, por fim, fazem amor na frente dele, colocando-o em estado contemplativo, obrigando-o a apenas "assistir" elas encontrarem a satisfação.

Inconformado com a atitude das esposas, Xavier, na tentativa de voltar a exercer o controle, não cumpre sua promessa de fidelidade e volta a procurar a prostituta. É o suficiente para inflamar, ao extremo, o sadismo das duas mulheres:

Carmem realmente inspirou-se.

Disse para Beatriz:

- Há na cozinha dois facões.

- E daí?

—E daí nós somos duas e temos dois facões. (LISPECTOR, 1998, p. 25).

A vontade que as mulheres sentem de assassinar Xavier vem, na narrativa, mais uma vez, representada pela apropriação de um símbolo fálico: 0 do facão. Para Jean Chevalier e Alain Gheerbrant (2012, p. 414), o simbolismo geral dos objetos cortantes é o do princípio ativo "modificando a matéria passiva [...] é o simbolismo fálico da faca, tão frequentemente evidenciado por Freud na interpretação dos sonhos de seus pacientes".

Ao escolherem um instrumento perfurador, cortante, sanguinário, causador de muita dor para aniquilar Xavier, notamos que a morte, através de um instrumento como o facão, não só traz à tona a imagem do poder do falo, da 
dominação masculina, da supremacia social do homem e do culto ao pênis, como expõe toda a carga de agressividade contida em todas essas instâncias:

\begin{abstract}
Foram armadas. $\mathrm{O}$ quarto estava escuro. Elas faquejaram erradamente, apunhalando 0 cobertor. Era noite fria. Então conseguiram distinguir o corpo adormecido de Xavier. O rico sangue de Xavier escorria pela cama, pelo chão, um desperdício. (LISPECTOR, 1998, p. 26).
\end{abstract}

Ao se apropriarem do facão/falo para executarem o próprio homem que Ihes causara mal, Carmem e Beatriz demonstram, inicialmente, pouca habilidade para com este instrumento representante da dominação masculina: "faquejaram erradamente, apunhalando o cobertor." Mas, ao conseguirem, finalmente, assassinar Xavier com golpes perfurantes, as duas mulheres demarcam o desvio dos impulsos sádicos anteriormente voltados para si mesmas e os destinam, com toda a agressividade, para o seu objeto sexual: penetrado enquanto dormia pelos facões-falos empunhados por suas mulheres, Xavier, passivamente, ocupa o posto que nunca achara que um dia seria seu - o da subjugação total perante os seres femininos.

Após cometerem o crime, as duas mulheres cavam uma cova no jardim da casa e enterram o corpo sem vida do ex-esposo. Velam o finado até o nascer do dia. No amanhecer, recolhem mudas de um roseiral e plantam-nas sobre a cova do defunto.

O conto encerra com a chegada da polícia na casa das duas, após terem recebido uma denúncia do secretário de Xavier preocupado com o seu paradeiro. $E$, sem relutarem ao que poderia thes ocorrer, mais uma vez resignadas, Carmem e Beatriz confessam o crime cometido para os policiais, apontando o local exato onde esconderam o corpo do ex-marido.

- Vocês duas, disse o outro policial, arrumem as malas e vão viver em Montividéu. Não nos deem maior amolação.

As duas disseram: muito obrigada.

E Xavier não disse nada. Nada havia mesmo a dizer. (LISPECTOR, 1998, p. 28).

E assim é finalizada a narrativa. Carmem e Beatriz, após anos de humilhação, dores psíquicas e sujeição, encontram a possibilidade do prazer e 
da liberdade longe da casa e do homem que um dia as dominara. Em suas biografias, os abusos que sofreram, crime que praticaram, a impunidade do homicídio que cometeram, e a última lembrança de um Xavier morto, sem "nada para dizer", na posição passiva, inerte e subalterna da qual ele tanto lutara para fugir.

\section{Considerações finais}

O uso do texto literário "O corpo", escritor por Clarice Lispector, reforçou, nesta oportunidade, a importância de se estabelecer leituras psicanalíticas de narrativas ficcionais. Ainda que as personagens Xavier, Carmem e Beatriz não compusessem o âmbito da nossa exterioridade, foram capazes de, sem precisarem deitar em um divã, conferir, através de um narrador articulado, o material necessário para atribuirmos sentidos psicanalíticos ao que fora representado.

As teorias levantadas por Freud (2016) a respeito do masoquismo e do sadismo foram possíveis de serem aplicadas, constatadas e comprovadas no comportamento das personagens criadas por Clarice. Também pudemos perceber, através das personagens de Xavier, Carmem e Beatriz, a atitude pendular do masoquismo e do sadismo, dificilmente fixos em uma única posição.

As relações de poder entre os gêneros evidenciaram, em conformidade ao defendido por Laplanche (2016, p. 468), que o lugar de quem exige é virtualmente um lugar de "perseguido-perseguidor, porque a mediação da exigência introduz necessariamente as relações sadomasoquistas do tipo dominação-submissão que toda a interferência do poder implica”. Sendo assim, acabamos por testemunhar uma alternância de poder entre um homem e duas mulheres que, ao se sentirem perseguidas, deram início a uma trágica perseguição.

Tal acontecimento talvez não tivesse sido possível, porém, se Carmem e Beatriz não tivessem se unido em relações afetivo-sexuais pois, ao modificarem a maneira como se relacionavam, romperam com o padrão estabelecido com Xavier que as condicionava a sempre desempenharem o papel de masoquistas. 
Por fim, tivemos, neste estudo, um breve panorama do corpo em seus desarranjos pulsionais, "na tirania de seus desejos, nas suas fraturas e feridas, nos seus êxtases. O corpo como bênção e maldição. Como tudo que excede, o que sobra, mas que não chega nunca a suprir a falta primordial”. (CHIARA, 1998, s/p.). Pois, como questionara a própria Clarice Lispector (1998, p. 12), em sua já referida "Explicação":

"Que podia eu fazer? senão ser vítima de mim mesma".

\section{Referências}

BIRMAN, Joel. As pulsões e seus destinos: do corporal ao psíquico. Rio de Janeiro: Civilização Brasileira, 2009.

CHEVALIER, Jean; GHEERBRANT, Alain. Dicionário de símbolos. Rio de Janeiro: José Olympio, 2012.

CHIARA, Ana Cristina de Rezende. Orelha de livro. In: LISPECTOR, Clarice. A via crucis do corpo. Rio de Janeiro: Rocco, 1998. s/p.

FREUD, Sigmund. Obras completas, volume 6: três ensaios sobre a teoria da sexualidade, análise fragmentária de uma histeria ("O caso Dora") e outros textos (1901-1905). São Paulo: Companhia das Letras, 2016.

KRAFFT-EBING, Richard von. Psychopathia sexualis. São Paulo: Martins Fontes, 2001.

LAPLANCHE, Jean. Vocabulário da psicanálise. São Paulo: Martins Fontes, 2016.

LISPECTOR, Clarice. A via crucis do corpo. Rio de Janeiro: Rocco, 1998.

MCWILLIAMS, Nancy. Diagnóstico psicanalítico: entendendo a estrutura da personalidade no processo clínico. Porto Alegre: Artmed, 2014.

QUINODOZ, Jean-Michel. Ler Freud: guia de leitura da obra de S. Freud. Porto Alegre: Artmed, 2007.

RALLO, Élisabeth Ravoux. Métodos de crítica literária. São Paulo: Martins Fontes, 2005. 